\title{
Vocal Ornamentation in the 18th century - Tosi and Mancini, first Theorists of Bel Canto
}

\author{
Mihaela-Elena BĂJEA (STANCIU) ${ }^{1}$
}

\begin{abstract}
In a time of change, the two great vocal singing theorists, Tosi and Mancini, wrote their theoretical papers with the stated aim of clarifying for both students and their tutors what they considered to be good landmarks in that era. Too much freedom in ornamentation, through an abusive and discretionary use, highlighted more the virtuosity of the singers than the melodic line in the context of words and music. Thus, forced by circumstances, the two authors tried to develop, in the 18th century, a methodology capable of balancing freedom of expression with theoretical rigor. Their effort was directed towards collecting and organizing the data available at the time about the mechanics and theory of ornamentation applicable to the principles and rules of harmony, while supporting freedom of expression and variety of inventiveness and having as sole purpose the beauty of sounds harmoniously intertwined with expression. They evaluated and criticized their contemporaries, highlighting both the defects and abuses of vocal performances, considering as the only point of reference the balance of expression subordinated to the fundamental elements of vocal precepts considered at that time true axioms. They generously offered their knowledge and science with the ultimate goal of creating a vocal show based on balance, beauty and spontaneity.
\end{abstract}

Key-words: Messa di voce, Appoggiatura, Volatina, Arpeggiatto, Scaletto.

\section{Introduction}

The vocal style of the Neapolitan School, representing the basis of bel canto style, is characterized by vocal embellishment, florid writing and coloratura, much of which was improvised by the singers. For the Neapolitans, ornamental virtuosity was of great importance, a virtuosity that in the eighteenth century was pushed to its maximum limits of difficulty and performance (Miller 1962, 75-76). The beauty of singing resulted both from individual expressiveness as well as from the series of conventions and rules of the time. The aura of mystery and legend of this period

${ }^{1}$ PhD student at Transilvania University of Brașov-Romania, miky1203@yahoo.com 
often created much confusion in understanding how teachers guided their disciples.

There are two theorists who clearly define the course of vocal ornamentation in the eighteenth century: Pietro Francesco Tosi born in Bologna in 1647 and deceased in London in 1727 and Giovanni Battista Mancini born in Ascoli in 1714 and deceased in Vienna in 1800.

Pietro Francesco Tosi was a castrated soprano, opera singer, but excelling in chamber music. He had a prestigious activity in London where he also wrote his journal of observations on vocal flourishes, Opinioni de cantori antichi e moderni o sieno osservazioni sopra il canto figurato, printed in 1723 with a series of seven own Cantatas for voice and harpsichord. This volume was translated into English in 1743 and into German in 1757 (Groves' Dictionary of Music).

Tosi's remarks on the art of singing and the principles that govern it are enunciated in an astonishing way: "Mind this, o my beloved Singers! For it is to You only, who are inclined to study, that I have addressed myself. This was the Doctrine of the School of those Professors, whom, by way of Reproach, some mistaken Persons call Ancients. Observe carefully its Rules, examine strictly its Precepts, and if not blinded by Prejudice, you will see that this School ought to sing in Tune, to put forth the Voice, to make the Words understood, to express, to use proper Gesture, to perform in Time, to vary its Movement, to compose, and to study the Pathetick, in which alone Taste and Judgment triumph." (Tosi 1743, 179-180)

Giovanni Battista Mancini was a disciple of Leonardo Leo and Padre Martini. He settled in Vienna in 1760 as a professor of the royal princesses. He printed his reflections and conclusions on figurative singing - Reflesioni praticahe sul Canto figurato - in 1774, with a reprint in 1777 (Groves' Dictionary of Music and Musicians). The technical principles of Tosi and Mancini were formulated and used in what is commonly called the Age of Bel canto. The correct performance of eighteenth-century music, however, requires a thorough understanding of what was considered at the time to be a good interpretation of music: expressiveness, good taste, and moderation in the use of the ornate song.

\section{Types of ornamentation recommended by Tosi and Mancini \\ 2.1. Messa di voce}

Messa di voce was the art of increasing or decreasing sound intensity on a longlasting sound. This term was frequently used in the Italian school of canto. It was a free, clear and natural way of emitting the sound of singing (Groves' Dictionary of Music and Musicians) 
Messa di voce was one of the means by which a student tried from the first lessons to develop the volume of his voice, consolidating his voice by learning the art of "bringing it forward". ("Putting the voice forward" is an expression frequently used by the masters of the Italian school of canto, which means to sing clearly, naturally and freely) (Litante 1962, 5). To perform messa di voce the student began to sing by making a soft sound at the beginning which he gradually increased in sound intensity, returning at the end to the same soft emission.

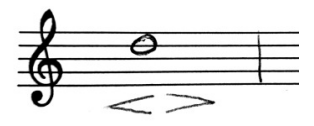

Fig. 1. Messa di voce

This had to be done on an open vowel, the final effect being very nice. If used too often, this process could become tedious (Mancini 1777 [1967], 27).

Messa di voce had to be used in moderation, by preserving the breath, in order to have a perfect control of the emission, using for this an open vowel. The double utility consists both in the development of the voice and in the expression of an intensified emotion using a single note. It was recommended to use it on the open vowel "a" (possibly on "e", but never on "o") (Brandon 1970, 12).

\subsection{The Appoggiatura (Appoggiatura)}

In the second chapter of his book, Opinioni de cantori antichi e moderni o sieno osservazioni sopra il canto figurato, Tosi suggests that the material on appoggiatura be studied last, although from a vocal point of view, this ornament was considered to be the first to be addressed (Mancini 1967, 58).

The function of the appoggiatura was perceived as a technique that could lead a song to perfection, without it the music would be "bland and tasteless". In his theoretical work "On the unity of the two registers, the portamento of the voice and the appoggiatura", Mancini argued that the appoggiatura can only be well understood and appreciated in close connection with the portamento. "By the portamento of the voice nothing can be understood other than the passage of the voice from one note to another through a perfect proportional union both in ascent and descent" (Mancini, 111). Before the portamento was made, the registers had to be reunited perfectly. This portamento required a solid breath, only after the student succeeded in being able to proceed to the execution of that appoggiatura. Mancini meant by appoggiatura a group of notes divided into singles, doubles and grupettos (Brandon 1970, 21). 


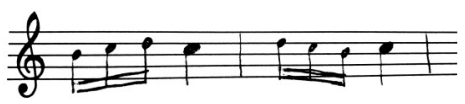

Fig. 2. The appoggiatura

Excessive accentuation of the appoggiaturas tended to overload and distort the proportion of the entire musical line, which could lead to an unpleasant use of the ornament. Mancini warned singers to use the appoggiatura only in an expressive and singable manner, and in words that evoked gentleness or tenderness (Mancini, 114). Special attention was paid to the appoggiaturas in recitatives, it being used only in those places where each note corresponded to a syllable of a word. This is only if it was included in the natural declamation, intentionally noted by the author.

The appoggiatura being the first type of ornamentation taught, first by Tosi and later by Mancini, the idea of portamento was emphasized; in slipping on a vowel, both in ascending and descending direction, the portamento being a sinequa-non condition necessary for mastering this type of ornament.

The ways in which this was done were different, with different rules as well. Mancini argued that a lower appoggiatura reaches the upper real note through a semitone, which is the only possible interval that can be used, while Tosi referred to the basic rules of music science regarding tonal intervals indicating that an appoggiatura could be used linked to a more distant note, provided that the interval between the appoggiatura and the actual sound is not dissonant (for example, increased fourth). Unlike Tosi, Mancini mentioned that the ascending course is possible at the semitone interval, and the descending one at the tone interval.

While Tosi was preoccupied in detail with appropriate intervals, Mancini seemed to be more interested in the expressive use of the appoggiatura. However, both masters were aware that the appoggiatura was often used inappropriately. For Mancini the bad taste was obvious when the musical text was "overloaded" with appoggiaturas, while in Tosi the interval used as appropriate was important, both authors emphasizing the need for naturalness (Brandon 1970, 20).

\subsection{The Trill}

At the time, it was mentioned that only through diligent and patient practice could the singer learn this difficult, but essential ornament. If a singer perfected his trill by singing it well, even if he lacked the other skills, he would still have made a pleasant impression. If in the interpretation of a piece this ornament had been omitted, its absence would have been obvious, even if the other ornaments had been executed perfectly (Aldrich 1942, 11). The trill was essential in a cadence and 
Vocal Ornamentation in the 18th century - Tosi and Mancini, first Theorists of Bel Canto 25

needed preparation (by the appoggiatura or messa di voce), provided there was time for it. Tosi suggested that the teacher should use verbal instructions, vocal, or instrumental examples to teach students the trill. He urged the teacher "to make efforts for the student to obtain an equal trill, distinctly marked, light and clear, of a frightening quality "(Tosi, 48).

Mancini claimed that the trill "signifies perfection, beauty and the ultimate goal of singing" (Mancini, 128). If the trill was not natural in voice, the teacher would be too tired and the student would be discouraged. Thus, the trill could be neglected, its importance in singing becoming insignificant. Mancini considered this to be a waste of potential that could become harmful to the voice itself. He also stated that "years of study of these elements of the art of singing are needed to strengthen a solid foundation for creativity" (Mancini, 123).

The universal law of the trill was that it is practically made up of a basic "real" note, to which is added a "false" note (The Concise Oxford Dictionary of Music). The trill began on the "false" note and ended on the "real" note. The "false" note was always one step higher than the "real" note, both having the same sound intensity. The trill was considered effective in itself, but due to its many hypostases it could direct students attention to covering the defects mentioned above by Tosi.

Mancini selected three of the most difficult types of trills, while explaining why they are difficult and awkward. The first of these types was the "crescendo" trill and the ascending crescendo trill.

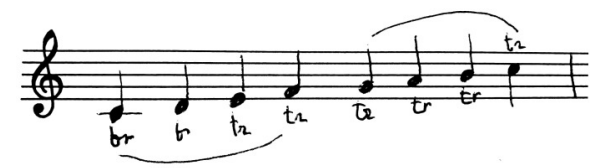

Fig. 3. The ascending crescendo trill

The second is the "colato" or diminished trill, on the descending tonality.

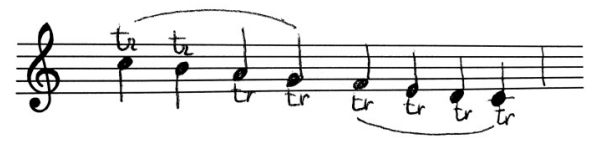

Fig. 4. The "colato"

Finally, the third is the so-called "trillo-raddappiato", or the redoubled trill (Mancini, 133 - 140). 


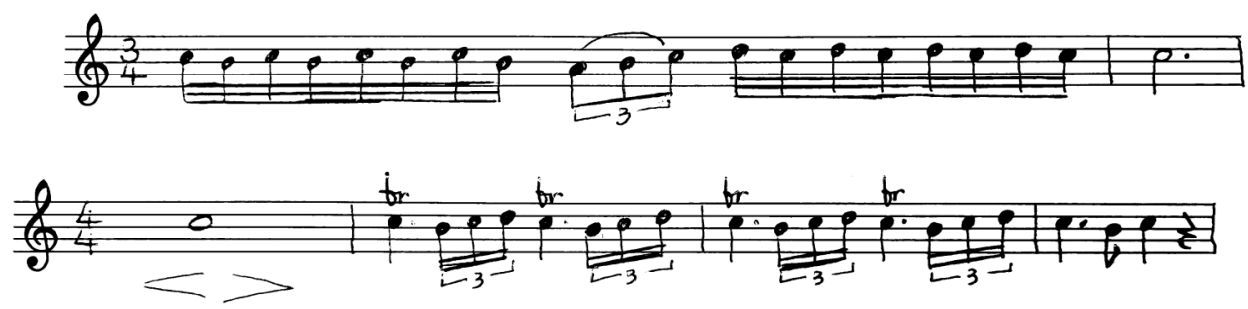

Fig. 5. The "trillo-raddappiato"

The latter had to be performed on a single breath with a perfect balance of voice. The Messa di voce did not have to consume so much air that there was not enough breath left to perform the added redoubled trills. Mancini instructed the students to give importance to the trill in a cadence, offering the following solution as optimal and beautiful enough: "I assert that a cadenza composed of two notes alone that is, a messa di voce... and a trill, is enough and remains perfect, complete and believable; but if it has only an appoggiatura, if it races toward the final note without a trill, everything falls apart, and remains imperfect" (Mancini, Giovanni Battista, p. 131). Mancini includes in this section of the trill a brief definition of the mordent. He sees the trill and the mordent as related types of ornamentation, the mordent being able to be used anywhere, being useful in any style of singing, if the voice has agility. "The mordent is born from the trill, this differs from the trill because ... the mordent is composed of a true note a half-tone below, and this false note should be struck more slowly and with less strength and less value than the real note..."(Mancini, Giovanni Battista, p. 136).

Very beautiful is also Tosi's next statement which is still valid today, according to which the trill is "determined by Practice, Good Taste and Knowledge" (Mancini, 140).

\subsection{Divisions and Passages}

Tosi states that "there are no differences between divisions and passages" (Tosi, 51). The "divisions" were not so much necessary for interpretation as they were necessary for the vocal capacity of a singer. They did not come from emotional expression, they did not touch the listener's feelings, except for the admiration for the singer's virtuosity. The well-executed "divisions" were admirable and a singer's ability to perform them had to be added to his ability to play in different styles.

Tosi considered the fluid and slow "divisions" to be "passages" and "flourishes." But the real "divisions" were the distinctly marked passages in a fast and lively tempo. There was an ease of voice at this speed, with all the notes sung 
distinctly and proportionally equal. There is a balance between too much legato and too much demarcation. The agility of a singer's voice was clearly noted in "divisions" and its practice developed vocal agility.

Any ornamentation could be fused with the "divisions", but at not too close distances, the rhythmic precision being absolutely necessary. This precision was noticeable in the slower passages, as well as in each subdivision, keeping the proportion ratio of the rhythmic symmetry.

The "divisions" were not easy and did not sound good at all on the Italian vowels " $i$ " and " $u$ ". In the best schools it was not allowed to use them even on " $e$ " or "o", especially when these vowels were either close or united. Other misuses of the "divisions", in addition to those mentioned above, regarding the execution of any ornament, were: abusing them, adding an " $h$ " to each note, using combinations of indistinct notes and inconsistent intonation. There were suitable places for the optimal use of "divisions", but also others completely unsuitable such as a Sicilian; the singer could destroy the composer's intention, where portamento and messa di voce were preferred (Brandon, 1970, 41).

The greatest danger in the use of "divisions" was the distortion of words, due to the numerous notes on a single vowel. Care had to be taken to preserve the real vowel, and where there were several vowels, they had to be clear and distinct. Unnecessary movements of the body, mouth or facial muscles were often responsible for the wrong execution of the "divisions", which could disrupt the vocal freedom so necessary for a perfect execution.

Tosi stated that the passages or flourishes are the "main" ornaments in singing. The singer should have learned this art that requires "judgment, invention, time, art and taste." The "judgment" came from study and practice, so that the passages seemed to be easily executed. The passages had to be created by individual "invention", which was as difficult as the singer's ability allowed, but far from anything vulgar and common. The quality of the "time" was necessary for the ordered metric flow. The loss of "time" in the passages made the singers lose the value of the expressiveness of the words. "Good taste" meant the correct use of the qualities mentioned above (Brandon 1970, 42).

Tosi has special tips for singers, about the passages in slow tempo. In a slow motion, there could be several passages, if the bass allowed. They should be soft or smooth to be effective. Sometimes a singer could use a "Strascino" or a "Drawing". 


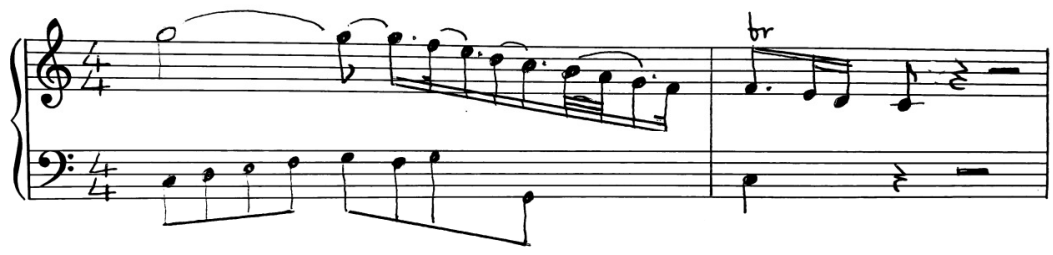

Fig. 6. The "Strascino"

Stracino was used when the bass had a slow, regular movement. The singer started with a high note, pulling it slightly down to a low note, starting with a forte and gradually diminishing the sound intensity of the passage. The passage was irregular, with uneven movement. This was the most effective ornament if the voice was left free and with enough time to reach the bass note. Stracino should not be used too often as it became monotonous or tiring but was effective in both ascent and descent (Brandon 1970, 42).

Passages should always be entered properly, with a light note.

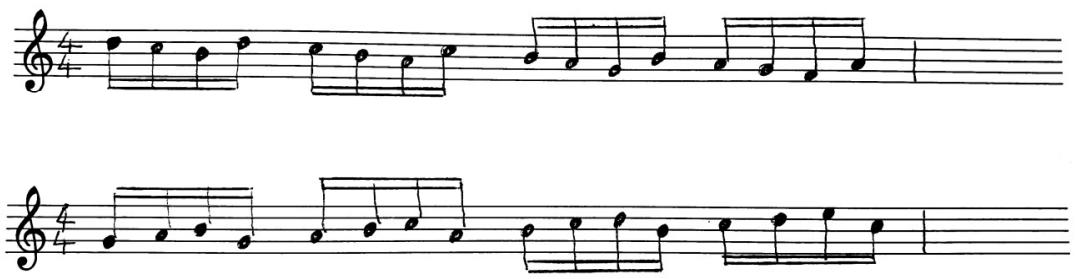

Fig. 7. Strascino

It had to be noticed if they were too frequent and with each new repetition they had to be improved. They were never supposed to be studied or mechanical. They were better when they were limited to a group of a few notes than when they were too crowded. In a fast tempo, the passages were more effective when they seemed "coloured" with light or dark shades, some softer notes and others with stronger notes, which Tosi called "Chiaro Scuro" (Brandon 1970, 44). Tosi said, “... they should proceed rather from the Heart than from the Voice, in order to make their way to the Heart more easily" (Tosi, 80).

Natural agility was rare, a gift to be encouraged when discovered in a voice. Mancini believed that if a voice was not agile, it should not have been forced, because forced agility was not pleasing to the ear, unable to strive for perfection. The amount of effort used in performance and in music practice in general should have depended on both the ability of the individual voice and the power to achieve 
Vocal Ornamentation in the 18th century - Tosi and Mancini, first Theorists of Bel Canto 29

the perfection to which a singer tended. The forcing of voice beyond its limits could have bad results though, even catastrophic ones.

"Volatina" was a simple passage of a range; even those with little agility had to perfect this passage.

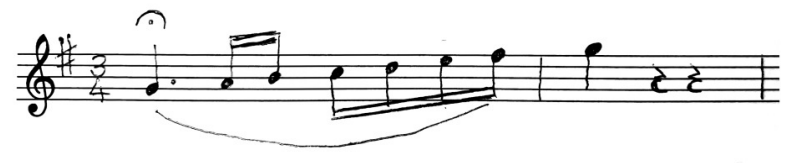

Fig. 8. The volatina

There were two types of volatina, both of which could go up or down. When the volatina exceeded one octave it was called "volatina raddoppiato" the doubled volatina (Mancini, 151).

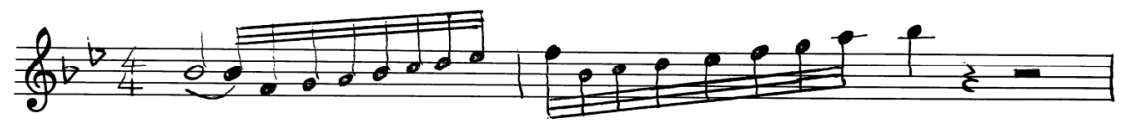

Fig. 9. The "volatina raddoppiato"

Mancini had a high esteem for volatina semplice, because it could be used in both a lively tempo and a more sustained one. If performed with an added trill, it could be used in many places, including cadences. The volatina could be started with a messa di voce preparing it. The voice was then calmed down and calm for the scaletta. In cadence, the rhythm was delayed in proportion to the final grade (Brandon, 45-46).

A technical procedure in the use of passages, requiring a very agile voice was that of the arpeggiato (Mancini, 156).

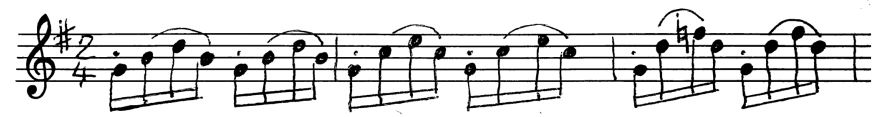

Fig. 10. The arpeggiato

This was a passage made from the sounds contained in a chord. This requires a natural disposition to agility, a very light and fast activity of the larynx. Performing this passage with perfect intonation is a very difficult thing, almost a record. 
Mancini suggested a moderate tempo starting with the first note scored, tying the next three. Another technical process of agility was "martellato".

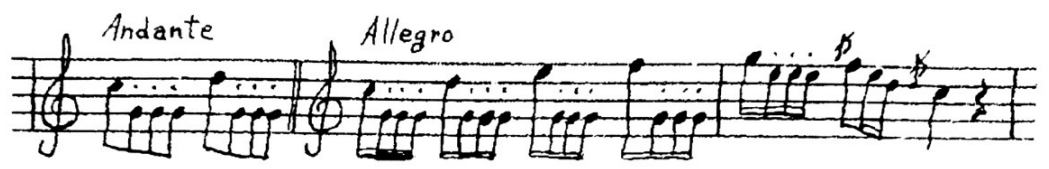

Fig. 11. The martellato

It consisted of beating each note several times, the first being more accentuated than the other three written on the same line (Mancini, 155). This process was also very difficult to perform and, as a result, was not promoted much by Mancini.

The ways of singing with leaps (cantar di sbalzo) was another technical ornamentation process that required agility (Groves' Dictionary of Music and Musicians)

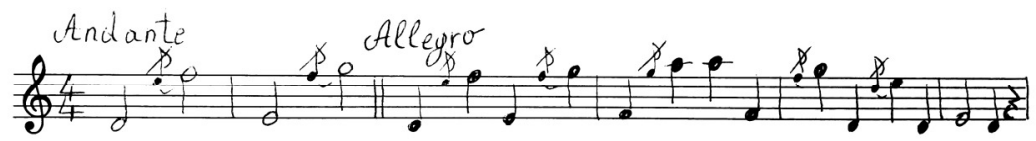

Fig. 12. Cantar di sbalzo

This process consisted of long or short-time values that, in order to be perfect, required a lot of skill and experience. The singer who performed this ornament had to have other qualities besides agility: to have a full, sonorous voice, with a good equality of registers. There were special intonation problems in this style. The notes did not have to be detached, they had to be studied with the help of the portamento to solve the wide intervals. The high notes had to be taken with the help of a lower appoggiatura. Mancini said: "...Taking the second note (which is the high note) without a vibrant appoggiatura makes it lose immediately its natural value, which is so necessary for this style of singing" (Mancini, 157-158). The exception occurred when the jump was made at the seventh or eighth interval. The effect was brilliant only if the jump at the seventh interval was made with the help of a appoggiatura and a portamento.

Tosi believed that divisions should be separated from passages, as they were different things. They are considered to be different, because the divisions evenly divide the passages that naturally make up a range, being more useful for the development of agility than for the performance itself. On the other hand, Mancini stressed the importance of vocalizing passages for the development of agility (as 
Tosi also remarks). Tosi admitted, however, that the divisions could be used with any other ornamentation. On the other hand, the passages, as Tosi describes them, could be slow, smooth and expressive, even if one of the main qualities he described, namely Chiaro scuro, could only manifest itself in a fast tempo. The expressiveness thus flowed from the musical colour based on the alternation of light and dark shades. Mancini called it the "colourful flourishes of the passages", in his description including all the tempos and all the types of scaletto under the title of "divisions". This is why both were considered one and the same thing, that is, "passages" (Brandon, 49).

\subsection{Cadenzas}

In a solo recitative or in an aria, the singer could choose between two types of cadences. If he was accompanied by instruments or other voices, the singer could not change these two types. The two types of cadences were the upper cadence and the lower cadence. In recitatives, the most common cadence was the interrupted cadence (The Concise Oxford Dictionary of Music)

Tosi considered that a cadence in which the vocal line descends with a fifth was irrelevant, except that it was light. However, he acknowledged that sometimes imitating words justified such a cadence (Tosi, 127-128). Each area had three final cadences: one at the end of the first part or section $A$, another at the end of the second part or section $B$ and a third at the end of the first part resumed which was called "da capo" (Harvard Dictionary of Music).

For him, the main, indispensable quality in case of using ornamentations, consisted in "expressing the voice in a pleasant way, by mean of appoggiaturas, getting from one note to another in an original and unexpected way, but precisely calculating and anticipating the bass movement" (Tosi 1743, 129). He also states that "filling" the cadence with many passages and divisions represented an old trick used by singers for getting applauses detrimental to expressing a beautiful and expressive music.

Another practice used was the use of the trill on the third, leaving the cadence unresolved.

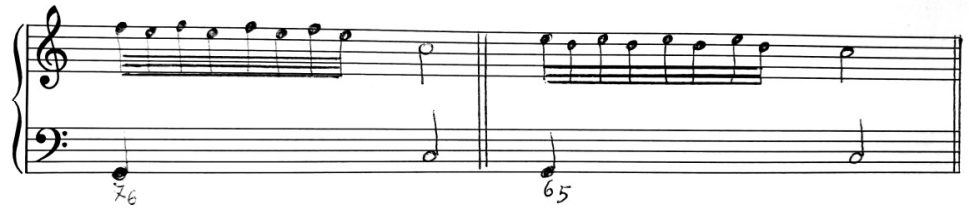

Fig. 13. Unresolved cadence 
The trill should have been solved by preparing it for a second (which was the sixth of the bass), thus allowing the fifth of the direct state agreement to be heard in the right place. It was absolutely forbidden to use trills or divisions on the last short syllable of a word; the trill or division had to be formed on the previous syllable.

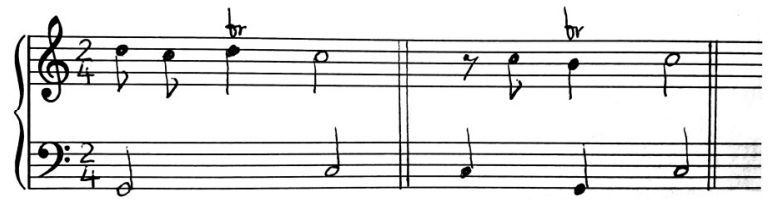

Fig. 14. Trills

According to Tosi, the ultimate flaw was to bore the listener with repeated cadences that sounded the same. The best singers of the time used variety repeatedly. Also, in each final cadence, the composers of the era generally left a note long enough to achieve a "discreet embellishment." Mancini stated that a cadence was needed to finish an aria, no matter how beautiful it was composed. An area could not be left incomplete, which is why a closing cadence is added. The cadence was to be a kind of "epilogue" of the area. It was necessary to start with a messa di voce, then move on to all the other figures and passages. It should not contain more notes than could easily be sung in one breath, including the trill, usually necessary at the end (Mancini 1967, 145).

\section{References}

Aldrich, Putnam Calder. 1942. The Principle Agrements of the Seventeenth and Eighteenth Centuries: A Study in Musical Ornamentation. Ph.D. dissertation, Cambridge, Mass.: Harvard University.

Brandon, Beverly Ann. 1970. Ornamentation of Italian Vocal Music of the Eighteenth Century According to Pietro Francesco Tosi and Giovanni Battista Mancini. University of North Dakota.

Groves' Dictionary of Music and Musicians. 1954. London: MacMillan, vol. 2; vol. 6. Harvard Dictionary of Music. 1962. Cambridge: Harvard U. Press.

Litante, Judith. 1962. Natural Approach to Singing. London: Oxford University Press.

Mancini, Giovanni Battista. 1967. Practical Reflections on Figured Singing. Vienna, 1777 (Transl. by Edward Foreman). Champaign: Pro Musica Press.

Miller, Hugh Milton. 1962. History of Music, (third edn.). Barnes \& Nobel.

The Concise Oxford Dictionary of Music. 2000, 2003. Oxford University Press.

Tosi, Pietro Francesco. 1743. Observations on the Florid Song or Sentiments on the Ancient and Modern Singers: Trans. Galliard. London. 